\title{
The company you keep: How network disciplinary diversity enhances the productivity of researchers
}

\author{
Dr. Tsahi Hayat, Sammy Ofer School of Communications, Reichman University, Herzliya P.O box 167, Israel \\ Email: tsahi.hayat@idc.ac.il
}

Dr. Dimitrina Dimitrova, Ryerson Sociology Department, 350 Victoria Street, Toronto, ON, Canada M5B 2K3 Email:dima@chass.utoronto.ca

Prof. Barry Wellman, NetLab Network, 1001-55 Prince Arthur Ave, Toronto, ON, Canada M5R 1B3

wellman@chass.utoronto.ca

\begin{abstract}
The Covid-19 pandemic has affected most organizations' working environment and productivity. Organizations have had to make provision for staff to operate remotely following the implementation of lockdown regulations around the world, because the pandemic has led to restrictions on movement and the temporary closure of workplace premises. The purpose of this paper is to gain a deeper understanding of the effect of this transition on the productivity of work during the pandemic, by studying a distributed network of research who collaborate remotely. We examine how the productivity of researchers is affected by the distributed collaborative networks in which they are embedded. Our goal is to understand the effects of brokerage and closure on the researchers' publication rate, which is interpreted as an indicator of their productivity. We analyze researchers' communication networks, focusing on structural holes and diversity, and we take into account the personal qualities of the focal researcher such as seniority. We find that disciplinary diversity among researchers' peers' increases the researchers' productivity, lending support to the brokerage argument. In addition, we find support for two statistical interaction effects. First, structural holes moderate diversity so that researchers with diverse networks are more productive when their networks also have a less redundant structure. Diversity and structural holes, when combined, further researchers' productivity. Second, seniority moderates diversity; so that senior researchers are more productive than junior researchers in less diverse networks. In more diverse networks, junior researchers perform as well as senior researchers. Social capital and human capital are complementary. We conclude that the benefits of diversity on researchers' productivity are contingent on the personal qualities of the researchers and on network structure. The brokerage / closure debate needs a more nuanced understanding of causal relationships.
\end{abstract}

Keywords: research network, productivity, social capital, human capital, brokerage 


\section{Introduction}

With tight restrictions on the movement of people and closure of businesses, the COVID-19 public health crisis has quickly developed into an economic crisis. While working at home got relatively little attention before the crisis, it has become a key policy instrument used by governments across the world as a means of minimising the spread of the pandemic (Reuschke \& Felstead, 2020). When this paper was being written much of the world was zooming around, being locked into home by COVID-19. For many, this was not a new experience. We are fortunate in having been part of and studied such an internet-based network for more than a decadea Canadian consortium of computer scientists and social scientists. The Graphic, Animation, and New Media (GRAND) network was designed as a country-wide, government-funded, multi-disciplinary and multi-sector research network in Canada. GRAND sits at the crossroads of several important trends transforming knowledge creation processes in society: increasing collaboration, multi-disciplinarity, distributed nature, formalization of research structures, and a stronger emphasis on productivity. It is a test case for studying a critical phenomenon in society: the determinants of knowledge creation.

Knowledge creation - defined as the generation of new ideas from the novel combination of existing knowledge - has changed in several fundamental ways (Fleming, 2001). First, it is no longer the exclusive purview of scientists. Since popular writers, social scientists, and critics dubbed the society we live an information society that runs on knowledge economy (Drucker, 1969), knowledge creation activities became apparent in multiple social domains. Scientists and academics continue to generate new ideas in invisible colleges (Crane, 1972), scholarly networks, research teams, and a range of new collaborative institutions online and offline (Bos et al., 2008).

In addition to science and academe, knowledge activities firmly entered workplace and organizations. If the employees of traditional bureaucracies were cogs in a complex but predictable machine, the employees of current post-bureaucratic organizations are often innovators and learners. The new organizations highlight the existence of knowledge networks, innovation processes, learning, and creativity in organizations: processes that include knowledge creation as one of its components. That is why today's knowledge creation can be observed and fruitfully studied in scientific institutions, academic research in higher educational institutions, innovation teams and innovation alliances in business, or government funded research networks such as the GRAND network we have studied.

The second critical change in knowledge creation and its theorizing is the recognition of its social nature. Until several decades ago, up to the 1950s, researchers treated the generation of knowledge much like the proverbial apple falling on Newton's head: a solitary endeavour of a brilliant mind and a single discrete event. Today, knowledge creation is seen as a collective process situated in social context (Binz-Scharf et al., 2015). Knowledge is born in the creative clash of diverse ideas and in the interactions of knowledge creators. Recent trends in the way scientific research is being organized and conducted bring this social nature more into focus. While knowledge creation has never been a solitary act, researchers increasingly work collaboratively. Collaboration and its results play out differently depending on national and disciplinary context; in developed countries, researchers work in one or multiple teams that might themselves be embedded in larger collaborative networks (Cummings \& Haas, 2012). Collaboration and co-authorship tend to span disciplinary, organizational, and geographic boundaries to enable sharing of resources and exchanging diverse ideas (Olson et al., 2008). In organizations, innovation follows several similar trends, reinforcing the idea that knowledge processes are socially situated. Employees manage complex networks or multiple teams and rely on information from their contacts to get their work done (Aral \& Van Alstyne, 2011).

The increasing size of collaborations spurred the yet another change in knowledge creation activities: the distributed nature of collaboration and the increasing reliance on technology. Long before COVID-19 made in- 
person meetings hazardous, researchers used online tools for data sharing, communication, remote access to facilities/equipment, and dissemination. They even searched for collaborations to be done online (Stark et al., 2020). Open labs, distributed research centers, and distributed research networks such as GRAND exemplify these trends (Bos et al., 2008). The COVID-19 pandemic further accelerated the trend to remote work and communication. Researchers found new ways to collaborate remotely under the new conditions, creating informal online collaboration networks to tackle the global issue of the pandemic (Rempel, 2020), and changing publication practices (Homolak et al., 2020). Researchers refer to it as e-science or cyberscience; each term draws attention to a specific aspect such as the virtualization (Olson et al., 2008), or the digital infrastructure for data collection, analysis, communication, and publishing (Binz-Scharf et al., 2015).

We identify in the multifaceted transformation of knowledge creation a shift to networked work and networked research (Dimitrova \& Wellman, 2015). Researchers and innovators are embedded in complex collaborative networks and rely on its resources to get their work done. They may juggle multiple teams, often distributed across several locations, overcome differences in time zones or culture, and rely on digital technology to communicate and accomplish tasks (Cummings \& Haas, 2012; Aral \& Van Alstyne, 2011).

Given the importance of knowledge creation in society and the complexities of its transformation, policy makers, businesses, and researchers themselves need to know how to improve research performance. We study the productivity of academics collaborating in distributed research networks. The broad concern of this analysis is to explore what factors contribute to successful knowledge creation. We argue that recognizing the social nature of knowledge creation helps us recognize its social determinants. If new ideas are generated in the interactions among knowledge creators, then the outcomes of creativity are contingent on the nature of the interactions as well as on a myriad of contextual conditions in which these interactions unfold.

In this analysis, we examine how the productivity of researchers is affected by the distributed collaborative networks in which they are embedded. To put it differently, we look at how research productivity depends on social capital. We start with the dominant debate in the literature of knowledge creation: the debate between brokerage and closure as two types of social capital that affect the generation of new ideas. We suggest that binary thinking, according to which new ideas benefits from either closure or brokerage, oversimplifies the existing causal relationships. To understanding the determinants of knowledge creation, we need a more complex interpretation of causal relationships that accounts for the structural properties of the networks, the properties of researchers themselves, and the broader contextual conditions in which collaborative research networks exist.

\section{Background and Literature Review}

The extensive literature on knowledge creation and its determinants is dispersed across several disciplines and research areas. We group them in three streams of research:

1) Studies of scientific teams and scientific networks, including research in the new field of team science (Hall et al., 2018), and co-authorship or collaborative networks (Lungeanu \& Contractor, 2015).

2) Closely related and overlapping with the first stream of research are studies on academic research, including scholarly networks (Wellman et al., 2014; Stark et al., 2020; Hayat et al., 2020; Cummings et al., 2013; Cummings \& Kiesler, 2007). In many cases, research networks include academics, government scientists, and industry researchers thus bringing together the first and the second research streams.

3) Organizational studies on innovation, knowledge networks, and individual and team creativity (Burt, 2004; Phelps et al., 2012; Perry-Smith \& Manucci, 2017).

Each stream of research has distinctive methods, ways of conceptualizing and theorizing phenomena, and analytical foci. Yet all they pursue similar concerns within the general phenomenon of knowledge creation. Each of them is in a position to contribute to understanding what contextual conditions impact creation 
processes. The review below draws on all three streams of research. Within this extensive literature, we concentrate on studies that examine how the networks of knowledge creators - whether scientists, academics, innovators, or creative employees - affect their productivity. Such networks reflect particularly vividly the social nature of knowledge creation and offer a systematic way to examine its importance. Our goal here is not a comprehensive review of all network properties that influence knowledge processes. (In a previous analysis, we reviewed studies on how collaboration, network size, diversity, and team composition, as well as network dynamics affect the performance of researchers (Hayat et al., 2020). This review focuses on brokerage and closure in order to understand better the causal relationships that determine the success or failure of knowledge creation.

\section{Brokerage and closure debate}

Literature on how social networks affect knowledge creation - whether in science, universities, or organizations - is dominated by the debate between brokerage (Burt, 2004, 1992) and closure (Coleman, 1988). Brokerage and closure are treated as two types, or sometimes two aspects, of social capital (Rost, 2011). The brokerage argument examines sparsely knit network structure characterized by disconnects, or structural holes; the closure argument explores densely knit bounded groups. Each type of network structure co-varies with a set of structural and relational properties. Structural holes go hand in hand with large size, diversity, bridging and weak ties. In contrast, closure and density track strong ties, frequent communication, and centrality (Rost, 2011). Brokerage and closure are negatively correlated. Increasing one set of characteristics - e.g. structural holes, size, diversity, and weak ties, tends to decrease the second set of characteristics - density, strong ties, and centrality (Aral \& Van Alstyne, 2011).

According to Ronald Burt's structural hole theory (2004) people who straddle the boundaries of disconnected groups and occupy bridging positions in a network are more likely to have creative ideas and their ideas are valued more highly by people around them. Brokers enjoy both information and control benefits: they have access to novel, non-redundant information or other resources and, in addition, control the flow of such resources in the network. In this framework, central for knowledge creation is information diversity. Structural holes and weak ties ensure that network members do not share knowledge, thereby making it redundant. Compositional diversity means that members themselves possess diverse skills and expertise and size correlates with more structural holes, weak ties, and diversity.

Several studies have demonstrated the positive impact of structural holes on generating new ideas. Mexican researchers with structural holes produced more publications (Gonzales-Brambila et al., 2013). Managers spanning structural holes generated more ideas and more valuable ideas (Burt, 2004). Associated with brokerage are network diversity and size. Knowledge diversity - most often measured as disciplinary or field diversity - in collaborations contributes diverse ideas and leads to more publications (Lungeanu \& Contractor, 2015). Further, increased diversity within an ego network contributes to the generation of innovative ideas (Hayat et al., 2020; Florida, 2004; Guimera et al., 2005). While scientists prefer coauthors with prior collaboration experience or similar ethnic backgrounds, publishing in high impact journals is associated with diverse backgrounds and diverse locations of team members (Liang \& Liu, 2018; Binz-Scharf et al., 2015; Fiscarelli et al., 2020). Finally, size matters, partly because it is associated with diversity. Larger teams bring together more diverse information and more resources which can positively affect innovation (Hulsheger et al., 2009) and scientific productivity (Cummings et al., 2013).

At the opposite side of the debate, the closure argument focuses on benefits such as trust, reciprocity, and collaboration in tightly knit groups (Coleman, 1988). Most of the arguments for the positive impact of closure on knowledge creation are not related to diversity of information and resources - as in structural hole theory but to increased information flow. Participants in dense networks enjoy communication and coordination benefits and are highly motivated to avoid opportunistic behaviour and share resources, including information and ideas (Phelps et al., 2012). Strong ties, positively associated with network density, can also improve 
learning and new ideas by facilitating the transfer of tacit knowledge, reflecting more quickly changes in information, and assisting the integration of ideas (Lazega et al., 2016; Aral \& Van Alstyne, 2011; Han, Han \& Brass, 2014). Empirical research offers support for the closure argument. Dense scientific teams had higher productivity and produced higher quality output (Fiscarelli et al., 2021). Dense alliance networks improved firms' innovation (Schilling \& Phelps, 2007). Cancer researchers sought advice within dense subsets of their networks among homogeneous partners (Lazega et al., 2016). Studies also find benefits from strong ties. Strong ties increased the volume of communication among the employees of a recruiting firm and thus contributed more novel information than structural holes (Aral \& Van Alstyne, 2011). Entrepreneurs in biotech industry exchanged advice with their own strong ties (Lazega et al., 2012).

Rather than lending definitive support to one or the other side of the debate, research indicates that both brokerage and closure can induce knowledge creation and innovation. When Rost (2011) examined brokerage and closure simultaneously, she found quadratic effects of network size, tie strength, and density on the innovativeness of firms (Rost, 2011). "Balanced social capital" with moderate levels of structural holes and density provided the highest productivity in German auto industry. Strong ties provided more credible information and moved it faster, while structural holes provided bridges to other social groups but did not lead to any action.

Far from being two opposite ends of a single continuum, brokerage and closure work together to facilitate knowledge creation (Han et al., 2014). Each of them supports a specific aspect of the generation of new ideas: bringing together diverse ideas, on the one hand, and integrating them, on the other. The network variables associated with brokerage and closure - structural holes, size, diversity, density and tie strength - affect knowledge creation in a complex way that cannot be captured in "either-or" thinking.

\section{The contingent value of social capital}

A contingency approach to knowledge processes reveals more complex causal relationships. This line of reasoning suggests that the impact of brokerage and closure on knowledge creation depends on the context (Phelps et al., 2012; Perry-Smith \& Manucci, 2017). As early as 1988, James Coleman suggested that the benefits of brokerage and closure can materialize under different conditions. This is because contextual factors can make it more or less likely for researchers and innovators - as well as firms - to take advantage of the opportunities their network provides or to mitigate the costs of network creation and maintenance. Some researchers suggest that the area of knowledge creation research is still under-contextualized: they underscore the importance of formal and informal institutional context for understanding knowledge processes and outcomes (Phelps et al., 2012; Han et al. 2014).

There is significant empirical support for the contingent value of social capital for knowledge creation (Gonzales-Brambila et al., 2013; Phelps et al., 2012; Aral and Van Alstyne, 2011; Adler \& Kwon, 2002; Burt, 1997). In their study of a recruiting company, Aral and Van Alstyne (2011) argue that novel information comes from both diverse networks with structural holes and from strong ties with frequent communication that can transfer richer information and do it more often. Which of the two - structural holes or strong ties - provides more novel information depends on the information environment. Several contextual factors come into play: the overlap of information among network members, the breadth of their communication, and the speed with which information changes. If one's contacts have overlapping information, structural holes cannot bring novel information. Indeed, the higher the information overlap among network members, the less important structural holes spanning geographic locations and knowledge domains. Further, in environments with fast changing information, access to novel information benefited from strong ties and frequent contacts; in such conditions, weak ties spanning structural holes delivered outdated information (Aral \& Van Alstyne, 2011).

In terms of institutional context, studies may need to distinguish between organizational settings, on the one hand, and science and academic settings, on the other (Gonzales-Brambila et al., 2013). In science and 
academia, existing norms of open knowledge exchanges and less competition assist trust, cooperation, and coordination. That is why new information might be more valuable than good coordination and the benefits of structural holes might be more salient (Gonzales-Brambila et al., 2013). In organizations, by comparison, trust and cooperation are harder to achieve as firms and employees protect their intellectual property; under such conditions closure and strong ties become more important (Adler \& Kwon, 2002).

Other contingencies link social capital and human capital, the structural properties of the network and the personal properties of the knowledge creators and their network members. The tenure, education, or experience of researchers and their contacts can all moderate the impact of brokerage or closure (Zhou et al., 2015; Phelps et al., 2012; Fleming, 2007). Human capital has been linked to knowledge diversity of individual members. On the individual level, the broad experience of managers and their network contacts provided the diverse information needed for knowledge creation while density created the trust needed to share the information (Fleming, 2007). In turn, by increasing their employees' human capital, organizations reduced the need for external partners or social capital (Phelps et al. 2012).

Academic seniority and education can also impact knowledge creation. Where work teams are concerned, Han and his colleagues (2014) suggest that different types of human capital affect different types of social capital and knowledge creation. They differentiate between three types of knowledge diversity, or human capital: content of knowledge, level of knowledge, and mental models of collaboration, each affects the relationships team members create with each other in a distinct way. For instance, different mental models preclude bonding capital while different levels of expertise preclude bridging capital.

Human capital is multidimensional concept that can be implicated in both bridging and bonding social capital as well as in different mechanisms of knowledge creation: availability of diverse ideas, ability to integrate these ideas, or ability to contribute and collaborate to knowledge creation. Studies on how seniority affects individual publications offers opposite arguments: senior academics may be more productive because they have more expertise and larger networks yet junior academics may have higher motivation and more recent skills. Results vary: some find that senior academic have more publications while others find no difference in publications when endogeneity is considered but more citations for senior academics (Mishra \& Smyth, 2013). Such research, however, does not explicitly explore the interplay between seniority and social capital.

In short, to understand how social capital benefits knowledge creation in a distributed research network, we need to account for the information and institutional environment and the knowledge which network members possess. Our analysis therefore carries out an exploratory study addressing how contextual factors shape the way social capital functions in knowledge processes.

\section{Methods}

\section{The research context}

GRAND ("GRaphics, ANimation and New Media"), a country-wide research network, was funded by the federal government of Canada to conduct research in the area of digital media and technology. As part of a special government program, the network was expected to build partnerships across sectors and carry out multidisciplinary and multi-institutional collaborative research. From 2020 to 2015, the network spanned seven provinces and 26 universities across Canada and linked faculty, industry partners, and students in 34 research projects. Many of the founding members of GRAND knew each other. The original members invited past collaborators, co-authors, and former PhD students to join the network. Yet GRAND leadership worked hard to encourage new collaborations and facilitate the exchange of new ideas. Formal procedures promoted collaboration across disciplines and institutions: projects in the network could not be funded without including members from at least three universities and three disciplines. While more than half of the researchers and 
project leaders in GRAND were computer scientists, other researchers came from engineering, information science, social sciences and humanities, and a sizable group had a background in Media, Art and Design. On a day-to-day basis, researchers worked remotely but in-person contact was used almost as frequently as email to keep in touch. Internal GRAND events, student exchanges, conference attendance all served to boost such in-person meetings. GRAND's Annual Conference was an important event, where researchers could bump into their colleagues face-to-face and discuss updates of actual projects or ideas for new ones.

One of GRAND's projects was self-reflective: its goal was to analyze collaboration and communication among GRAND scholars themselves. As members of this project, aptly called NAVEL (Network Assessment and Validation for Effective leadership) we had unprecedented access to the inner working of a large-scale research networks such as GRAND. We collected data through two online surveys - one at the early stage of GRAND and a second one near its end, a series of in-person and phone interviews with network researchers, and observations at the meetings and events. This analysis draws on part of the data collected during the existence of the GRAND network.

Our research aims focus on the links between contextual factors and knowledge production. In the context of GRAND, a distributed research network comprised of academics, we expect higher cooperation and coordination and greater importance of brokerage and structural holes for creativity (Gonzales-Brambila et al., 2013). The impact of structural holes is contingent on the information overlap among network members (Aral \& Van Alstyne, 2011). We expect that the disciplinary diversity of network members leads to information diversity and boosts the benefits of structural holes. Hence, our first question is the following:

RQ1: How do the disciplinary diversity and structural holes of researchers' communication network interplay with the researchers' number of publications?

Our second concern is with the human capital and specifically with level of expertise of ego and network members. In teams, differences in level of expertise are expected to weaken bridging capital. For individuals participating in collaborative knowledge creation, the level of expertise may be associated with the ability to receive more diverse ideas, contribute one's ideas to the team, or to integrate diverse ideas thus amplifying the impact of knowledge diversity. Our second research question is:

RQ 2: How do the seniority and disciplinary diversity of researchers' communication network interplay with the researchers' number of publications?

\section{Data collection}

Surveys

To collect information about the structure of communication networks of GRAND members, we used data collected through two online surveys of the faculty researchers. In these surveys, we inquired about their age, gender, discipline, affiliation, etc., as well as their social and professional relations with other GRAND members. We asked all GRAND faculty members to participate in both surveys via an invitation email. We gave all participants a roster of GRAND members and asked them to identify GRAND members with whom they communicated, collaborated, exchanged advice and ideas, and with whom they were friends and acquaintances.

In this paper we focus on the communication networks of GRAND members. We used an established procedure in personal network survey research to make the completion of the survey easier. The respondents were first asked to identify all of their acquaintances (out of the entire population of GRAND faculty 
researchers), and then they were asked to provide information about those individuals whom they had identified as acquaintances rather than about the entire GRAND population (Wasserman \& Faust, 1994; Hogan et al., 2007; Wellman, 2007). We conducted the first round of the survey between September and November 2010, a few months after GRAND actually began. We first sent email invitations to all GRAND members at that time (144), and we increased the response rate by using email and phone reminders. A total of 101

researchers completed the survey, a participation rate of $70 \%$. A subsequent second survey made it possible to examine changes in the GRAND network. It was conducted after GRAND was well underway, between September 2012 and March 2013. To maintain consistency, we presented the same questions in the second survey as we had presented in the first survey. We invited all GRAND members via email to participate in the second survey: As additional researchers had joined GRAND, there were 208 GRAND members, and 124 completed the survey--a lower participation rate of $58 \%$ as the euphoria of being in GRAND had waned. The sample used in this study consists of the participants who completed both the first and second surveys $(\mathrm{N}=101)$.

\section{Web of Science (WoS)}

The Web of Science online citation service indexes authors, institutional addresses, and references for all article types (Mongeon \& Paul-Hus, 2016). We used WoS for the years 2015-2020 to discover publications that arose from GRAND after it had ended. 


\section{Measures}

\section{Communication}

The weighted and directed communication ties among GRAND researchers indicate both the media used and the frequency at which the media are being used for communication. Each GRAND researcher was asked in the first and second surveys to indicate the top three media they used for communicating with each other person in GRAND (i.e., in person, email, mobile phone, voice over IP, audio and video-conferencing, online forum, social networking sites such as LinkedIn, Facebook, and instant messaging). Frequency of communication was also gathered for each of the three media reported by the researchers who were asked to report how often they use each of the top three media: several times a day, about daily, weekly, monthly, a few times a year, yearly, less than once a year.

\section{Publications per Year}

Although research work has a variety of potential outcomes, many researchers distinguish between two main outcomes: publications and citations interpreted as productivity and impact (Halevi et al., 2016; Sarigol et al., 2014). The first output captures knowledge creation processes, the second output tracks knowledge diffusion. Given our interest in productivity, we focus on the number of publications. We used the WoS to identify each of the publications produced by each of the GRAND participants between the years 2015-2020, following the end of the GRAND project.

\section{Seniority}

The status of participants in a research team can affect how actively they contribute to the exchange of ideas and to the knowledge creation processes (Han et al., 2014). In academic settings, seniority reflects both the level of expertise and the status of the participants and can capture well the potential for disparate contributions. Seniority was assessed by asking our participants about their academic status (Assistant Professor, Associate Professor, Professor, and not relevant).

\section{Control Variables}

We used individual-level information that had been collected in the first survey: gender (men and women); age; and position within GRAND (Principal or Collaborating Researcher).

\section{Data Analysis}

We used ORA (Carley et al., 2012) and UCINET (Borgatti et al., 2002) software to analyze the ego level communication networks as well as to compute network properties for each GRAND member: diversity (Blau, 1977), and structural holes (Burt, 1992). We used two OLS regression models to address how the diversity and structural holes of researchers' communication network are associated with the number of publications (RQ1). We also explore how the seniority and disciplinary diversity of researchers' communication are linked to the number of publications they produce (RQ2). We calculated these models while controlling for the possible effect of gender, age, academic status, and status within GRAND. In the first block we entered the control variables. In the second block we entered the main independent variables separately (ego level diversity and structural holes measures). In the third block we entered interaction terms representing the main independent variables. We study the communication ego-networks for each GRAND member. Two network measures diversity, and effective network size - were calculated for the examined networks. These measures are discussed when addressing our research questions.

\section{Results}

\section{Sample description}

The participant researchers came from 26 universities dispersed in seven Canadian provinces. Their disciplinary background (see figure 1) included 46 from computer science, 14 from information science, 13 from arts and technology, 7 from social sciences, 6 from the humanities, and 15 from medicine, architecture, 
and other professions. Two-thirds (65) were male and 36 were female. The seniority of the participants was assessed according to their academic ranks, that is, assistant professor $(n=26)$, associate professor $(n=43)$, and full professor $(n=32)$.

To understand the link between the diversity of researchers' communication networks, their seniority, and the number of publications they produced, we measured the productivity of the researchers in terms of their scholarly publications, i.e., publications following GRAND (2015-2020). We then examined the extent to which seniority moderates the relationship between diversity and productivity. We estimate an OLS regression, predicting the productivity of a researcher, while controlling for sex, age, and discipline as well as the interaction between diversity and seniority. Model 1 shows the main effect of communication diversity, and Model 2 shows the interaction. Model 1 demonstrates that the diversity of communication connections built via GRAND continued to affect productivity even after its demise. The diversity of the communication network had an effect of $\beta=.61, t(90)=3.4, p<.05$, in terms of the future publication of GRAND researchers. Model 2 indicates that there is a significant interaction between communication diversity, seniority, and productivity. Specifically, according to the interaction plot (depicted in Figure 2) low levels of diversity yielded higher levels of productivity for senior researchers (when compared to less senior researchers). Yet, at high levels of diversity there was no difference in terms of productivity between senior and less senior researchers. Simple slopes tests, following Cohen et al. (2014), were conducted at one standard deviation both above and below the mean of the seniority score. Both slopes were significant $(p<.001)$.

\section{Insert Table 1 here}

\section{Insert Figure 2 here}

To tease out the effects of diversity and structural holes of researchers' communication network on the number of publications, we again measured the productivity of the researchers in terms of their scholarly publications, i.e., publications following GRAND (2015-2020). We then examined the extent to which structural holes in the communication network moderates the relationship between diversity and productivity. We estimate an OLS regression, predicting the productivity of a researcher, while controlling for sex, age, and discipline as well as the interaction between diversity and structural holes. Model 1 shows the main effect of communication diversity, and Model 2 shows the interaction. Model 1 shows that diversity of communication connections formed during GRAND continued to affect productivity even after GRAND ended. The diversity of the communication network had an effect of $\beta=.61, t(90)=3.4, p<.05$, over the future publication of GRAND researchers.

Model 2 indicates that there is a significant interaction between communication diversity, structural holes, and productivity. Specifically, according to the interaction plot (depicted in Figure 3) at low levels of diversity, structural holes played no significant role in effecting productivity. Yet, high levels of diversity yielded higher levels of productivity for researchers with higher structural holes scores (when compared to researchers with low structural holes scores). Simple slopes tests, following Cohen et al., (2014), were conducted at one standard deviation both above and below the mean of the structural holes scores. Both slopes were significant $(p<.001)$. 


\section{Insert Figure 3 here}

\section{Discussion}

The findings presented here are based of our examination of GRAND, a distributed multi-disciplinary research network. In a nutshell, our research confirms the benefits of brokerage for academic researchers and highlights the joint effects of social capital (i.e., diversity and structural holes) and human capital (i.e., seniority), on productivity. We can summarize our results in several main findings. First, we find that the disciplinary diversity of network members is associated with increased productivity in knowledge creation. In the context of academic research, novel information is more important than coordination benefits (GonzalesBrambila et al., 2013). Past research suggests that increased diversity within an ego network implies a mix of researchers from different backgrounds having different skills, abilities, information, and knowledge. Within such an environment, researchers are more likely to search for solutions that recombine previously disconnected ideas to generate knowledge and innovation (Florida, 2004; Guimera et al., 2005; Hayat et al., 2020). Large distributed multi-institutional research networks can potentially weaken coordination and increase opportunistic behavior (Cummings \& Kiesler, 2007). Such negative impact either did not materialize possibly due to the prior connections among GRAND researchers and the network wide opportunities for inperson meetings, or such negative impact was offset by the benefits of knowledge diversity.

Second, we further show that productivity increases when the connections of the focal researcher to colleagues from more diverse disciplines are characterized by a less redundant structure; structural holes enhance knowledge diversity. Previously, Aral \& Van Alstyne (2011 p. 139) have shown that structural holes are not useful without the heterogeneity of one's network contacts in terms of their expertise. No volume of structural holes can spur new ideas if the knowledge of network members overlaps. Our findings suggest that their logic applies to the opposite situation: if network members bring an abundance of diverse ideas, structural holes can assist in their utilization. By all means, understanding the effects of networks on researchers' productivity requires that we account for both the structural properties of the network (i.e., structural holes) and its composition (i.e., diversity). These results are consistent with arguments that the knowledge heterogeneity of network members serves as a mediator or an antecedent variable between structural holes and knowledge creation (Han et al., 2014). Further, we find that the knowledge diversity of network members functions differently on individual level compared to group level. In their study of project teams Han, Han and Brass (2014) demonstrate that the knowledge diversity of team members acted as an antecedent variable that assisted in the creation of bridging social capital, which enhanced the productivity of the team. In their interpretation, the team's joint human capital - understood as team members' knowledge heterogeneity - led to the creation of social capital. By comparison, we find that on individual level structural holes in one's collaborative network moderate the impact of disciplinary diversity on productivity. Future research may identify additional contingencies that bring forward different relationships between knowledge diversity, structural holes, and productivity.

Third, we demonstrate that knowledge diversity affects differently the productivity of junior and senior researchers. Diverse ego-networks can assist junior researchers to catch up with senior researchers; by contrast, lower diversity networks allow senior researchers to be much more productive than junior researchers. These results are especially intriguing since the relationship between seniority and network diversity, or human capital and social capital, is far from well understood. There is a compelling argument that senior researchers, drawing on their rich experience, should be able to better integrate diverse ideas then their junior peers and therefore should benefit more from diversity (Phelps et al., 2012). But this is not what happens in the network of GRAND. Senior researchers were more productive compared to their junior colleagues in low diversity networks. Past research suggests that academics prefer to work within their own discipline (Liang \& Liu, 2018). For senior researchers in GRAND, this seemed to be the winning strategy. Perhaps, as Aral and Van Alstyne (2011 p. 129) hypothesize, as individuals accumulate experience, they specialize and focus their work into fewer topics; they are more productive working with colleagues who are 
similarly focused in their work. It is also possible that in low diversity network - where the expertise of members overlaps - seniority becomes a more visible indicator of status and allows greater contribution (Han et al., 2014). Or perhaps senior researchers are simply able to compensate for the lack of diverse ideas coming from peers by drawing on the rich knowledge they have accumulated over time. Our results do not allow identifying the mechanism responsible for these results. By comparison, junior researchers are more productive working with more diverse colleagues; under such conditions they are able to reach the same level of productivity the senior researchers demonstrated. This might be a result of motivation. Junior researchers look for opportunities and information to compensate for their lower human capital (Mo et al., 2015). It is also possible that this is a result of flexibility: junior researchers benefit more from diversity because they are more open to new ideas and more open to multi-disciplinary collaborations (Hayat \& Mo, 2015). On a group level, in a diverse disciplinary network social status might be more strongly rooted in the area of expertise rather than in the seniority of researchers. In such a setting, junior researchers' contributions are valued as highly as senior researchers' contributions. Whatever the mechanisms, junior researchers benefited more from the disciplinary diversity of the network, when compared to their more senior colleagues.

Past research in organizational settings suggests that human capital and social capital are complementary (Phelps et al., 2012; Fleming et al., 2007). Our results confirm that the complementary relationship between human capital and social capital in academic settings. The knowledge diversity of network members, which serves as a source for social capital, compensated for junior researchers' lower human capital.

Our results have significant practical implications. For research policy, the findings emphasize the importance of looking at the functional aspect of diversity (Milliken \& Martins, 1996). Government and private funding agencies tend to fund proposals that bring together more disciplines, more institutions, and more locations; they require compositional diversity (Cummings \& Kiesler, 2007). The logic is that knowledge is diffused across locations and disciplines; drawing on a variety of locations, institutions, and disciplines will provide access to diverse knowledge. However, a policy approach rewarding diverse network composition erroneously assumes that the disciplinary diversity of network members is sufficient for multi-disciplinary collaborations because network members are equally connected to each other (Milliken \& Martins, 1996). Reality is different. A multiinstitutional, multi-location, and multi-disciplinary network does not mean that researchers will sort themselves into equally diverse collaborations, does not guarantee that an abundance of diverse ideas, nor does it ensure that those diverse contributions will come together in a creative discovery. Despite the strong mandate for multi-disciplinary projects in GRAND, not all members were able or willing to do so. Exploring research networks enables us to discard such unwarranted assumptions and focus on the actual connections. Another key takeaway of our results is the interaction of human capital and social capital in the process of knowledge creation and its implications for collaborative strategies. In the context of a multi-disciplinary multiuniversity research network, the qualities of researchers' collaborators are just as important as the structural properties of their networks. The interactive effects of network diversity and seniority sheds light on effective collaborative strategies. Past research suggests researchers prefer collaborators with whom they have prior experience and are from the same discipline (Binz-Scharf et al., 2015; Liang \& Liu, 2018; Dimitrova, Mok, \& Wellman, 2015). Retaining existing ties over time improves the number of publications but not necessarily their quality (Siciliano et al., 2018). It seems that for junior academics reaching across disciplinary boundaries can boost productivity.

By highlighting the interaction between the human capital of the focal researchers and their social capital, our findings allow us to reconnect the early ideas about knowledge creation as the independent work of a single brilliant mind and the later emphasis on the collective nature of knowledge creation. Newton, as the anecdote goes, came up with the idea on gravity while being physically away from his peers, fleeing the plague in London and leaving behind a locked down Cambridge University. Modern researchers, by contrast, work collectively; even the lockdowns of the COVID global pandemic did not stop but often spurred formal and informal collaborations (Siciliano et al., 2018; Binz-Sharf et al., 2015). As Simonen asserted: "A successful 
'social psychology of creativity' demands that the creative individual be placed within a network of interpersonal relationships" (1984: 1273). What our results suggest is that, in the modern context of collaborative research work, individual qualities continue to matter although they interact with the collaborative structures. 


\section{References}

Adler, P. S., \& Kwon, S. W. (2002). Social capital: Prospects for a new concept. Academy of management review, 27(1), 17-40.

Aral, S., \& Van Alstyne, M. (2011). The diversity-bandwidth trade-off. American Journal of Sociology, 117(1), 90-171.

Binz-Scharf, M. C., Kalish, Y., \& Paik, L. (2015). Making science. American Behavioral Scientist, 59(5), 531-547.

Blau P.M. (1977) Macrosociological theory of social-structure. American Journal of Sociology, 83, 26-54.

Borgatti, S. P., Everett, M. G., \& Freeman, L. C. (2002). Ucinet for Windows: Software for social network analysis. Harvard, MA: analytic technologies, 6.

Bos, N., Zimmerman, A., Olson, J., Yew, J., Yerkie, J., Dahl, E., \& Olson, G. (2008). From shared databases to communities of practice: A taxonomy of collaboratories. Journal of Computer-Mediated Communication, 12(2), 652-672.

Burt, R. S. (1997). The contingent value of social capital. Administrative science quarterly, 339-365.

Burt, R. S. (2004). Structural holes and good ideas. American journal of sociology, 110(2), 349-399.

Burt, R.S. (1992) Structural holes. Chicago: University of Chicago Press.

Carley, K., Pfeffer, J., Reminga, J., Storrick, J., \& Columbus, D. (2012). ORA User's Guide 2012. Pittsburgh, PA: Carnegie Mellon University.

Coleman, J. S. (1988). Social capital in the creation of human-capital. American Journal of Sociology, 94, S95S120. doi:10.1086/228943.

Crane, D. (1972). The Invisible College. Chicago: University of Chicago Press.

Cohen, P., West, S.G. \& Aiken, L.S. (2014). Applied multiple regression/correlation analysis for the behavioral sciences. Psychology Press.

Cummings, J. N., \& Haas, M. R. (2012). So many teams, so little time: Time allocation matters in geographically dispersed teams. Journal of Organizational Behavior, 33(3), 316-341.

Cummings, J. N., \& Kiesler, S. (2007). Coordination costs and project outcomes in multi-university collaborations. Research policy, 36(10), 1620-1634.

Cummings, J. N., Kiesler, S., Bosagh Zadeh, R., \& Balakrishnan, A. D. (2013). Group diversity increases the risks of large group size. Psychological Science, 24(6), 880-890.

Dimitrova, D., \& Wellman, B. (2015). Networked work and network research: New forms of teamwork in the triple revolution. American Behavioral Scientist, 59(4), 443-456.

Drucker, P. F. (1969). The knowledge society. New Society, 13(343), 629-631.

Fiscarelli, A.M., Brust, M., Bouffanais, R., Piyatumrong, A., Danoy, G., Bouvry, P. (2021). Interplay Between Success and Patterns Of Human Collaboration: Case Study Of A Thai Research Institute. Scientific Reports, 11, 318. DOI http://doi.org/10.1038/s41598-020-79447-z

Fleming, L. (2001). Recombinant uncertainty in technological search. Management Science, 47: 117-132.

Florida, R. (2004). The rise of the creative class and how it's transforming work, leisure, community and everyday life (Paperback Ed.). GEN, New York: Basic Books.

Gallivan, M., \& Ahuja, M. (2015). Co-authorship, homophily, and scholarly influence in information systems research. Journal of the Association for Information Systems, 16(12), 980.

Guimera, R., Uzzi, B., Spiro, J., \& Amaral, L. A. N. (2005). Team assembly mechanisms determine collaboration network structure and team performance. Science, 308(5722), 697-702

Halgin, D. S., Gopalakrishnan, G. M., \& Borgatti, S. P. (2015). Structure and agency in networked, distributed work: The role of work engagement. American Behavioral Scientist, 59(4), 457-474.

Hall, K. L., Vogel, A. L., Huang, G. C., Serrano, K. J., Rice, E. L., Tsakraklides, S. P., \& Fiore, S. M. (2018). The science of team science. American Psychologist, 73(4), 532.

Han, J., Han, J., \& Brass, D. J. (2014). Human capital diversity in the creation of social capital for team creativity. Journal of Organizational Behavior, 35(1), 54-71.

Hayat, T., Dimitrova, D., \& Wellman, B. (2020). The differential impact of network connectedness and size on researchers' productivity and influence. Information, Communication \& Society, 23(5), 701-718. 
Hayat, T., \& Mo, G. Y. (2015). Advice giving and receiving within a research network. American Behavioral Scientist, 59(5), 582-598.

Hogan, B., Carrasco, J.-C., \& Wellman, B. (2007). Visualizing personal networks. Field Methods, 19(2), 116-144.

Homolak, J., Kodvanj, I., \& Virag, D. (2020). Preliminary analysis of COVID-19 academic information patterns: a call for open science in the times of closed borders. Scientometrics, 124(3), 2687-2701.

Hülsheger, U. R., Anderson, N., \& Salgado, J. F. (2009). Team-level predictors of innovation at work. Journal of Applied Psychology, 94(5), 1128.

Lazega, E., Mounier, L., Snijders, T., \& Tubaro, P. (2012). Norms, status and the dynamics of advice networks. Social Networks, 34(3), 323-332. doi:DOI 10.1016/j.socnet.2009.12.001

Lazega, E., Bar-Hen, A., Barbillon, P., \& Donnet, S. (2016). Effects of competition on collective learning in advice networks. Social Networks, 47, 1-14.

Liang, X., \& Liu, A. M. (2018). The evolution of government sponsored collaboration network and its impact on innovation: A bibliometric analysis in the Chinese solar PV sector. Research Policy, 47(7), 1295-1308.

Lungeanu, A., \& Contractor, N. S. (2015). The effects of diversity and network ties on innovations. American Behavioral Scientist, 59(5), 548-564.

Milliken, F. \& Martins, L. (1996). Searching for common threads: Understanding the multiple effects of diversity in organizational groups. Academy of management review, 21(2), 402-433.

Mishra, V., \& Smyth, R. (2013). Are more senior academics really more research productive than junior academics? Evidence from Australian law schools. Scientometrics, 96(2), 411-425.

Mongeon, P., \& Paul-Hus, A. (2016). The journal coverage of Web of Science and Scopus: a comparative analysis. Scientometrics, 106(1), 213-228.

O'Leary, M. B., Mortensen, M., \& Woolley, A. W. (2011). Multiple team membership. Academy of Management Review, 36(3), 461-478.

Olson, G.M., Bos, N., and Zimmerman, A. (2008). Introduction. In Olson, Zimmermann, A. and Bos, N.: Scientific collaboration on the Internet, 2008, MIT Press, 1-12.

Perry-Smith, J. E., \& Mannucci, P. V. (2017). From creativity to innovation. Academy of Management Review, 42(1), 53-79.

Phelps, C., Heidl, R., \& Wadhwa, A. (2012). Knowledge, networks, and knowledge networks. Journal of Management, 38(4), 1115-1166.

Rempel, D. (2020). Scientific Collaboration During the COVID-19 Pandemic: N95DECON. org. Annals of Work Exposures and Health.

Reuschke, D., \& Felstead, A. (2020). Changing workplace geographies in the COVID-19 crisis. Dialogues in Human Geography, 10(2), 208-212.

Rost, K. (2011). The strength of strong ties in the creation of innovation. Research Policy, 40, 588-604.

Shilling, M. A., \& Phelps, C. C. (2007). Interfirm collaboration networks: The impact of large-scale network structure on firm innovation. Management Science, 53(7), 1113-1126.

Stark, T. H., Rambaran, J. A., \& McFarland, D. A. (2020). The Meeting of Minds: Forging Social and Intellectual Networks within Universities. Sociological Science, 7, 433-464.

Hayat, T., Dimitrova, D., \& Wellman, B. (2020). The differential impact of network connectedness and size on researchers' productivity and influence. Information, Communication \& Society, 23(5), 701-718. https: $/ / 10.1080 / 13698.118 x / 2020.1713844$

Wasserman S. \& Faust K. (1994) Social network analysis. Cambridge: Cambridge University Press.

Wellman, B. (2007). Challenges in collecting personal network data: the nature of personal network analysis. Field Methods, 19(2), 111-115. doi: 10.1177/1525822x06299133

Wellman, B., Dimitrova, D., Hayat, Z., Mo, G. Y., \& Smale, L. (2014). Networking scholars in a networked organization. In Contemporary perspectives on organizational social networks. Emerald Group Publishing Limited.

Zhou, W., Vredenburgh, D., \& Rogoff, E. G. (2015). Informational diversity and entrepreneurial team performance. International Entrepreneurship and Management Journal, 11, 39-55. 
Tables and graphs:
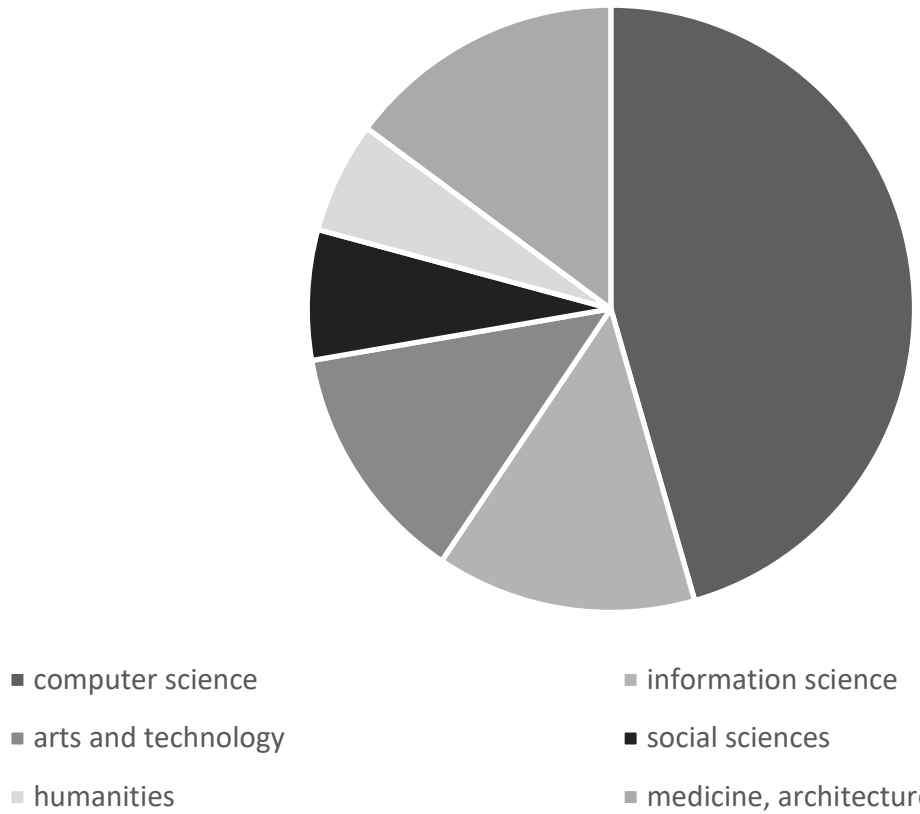

Figure 1: GRAND by discipline 


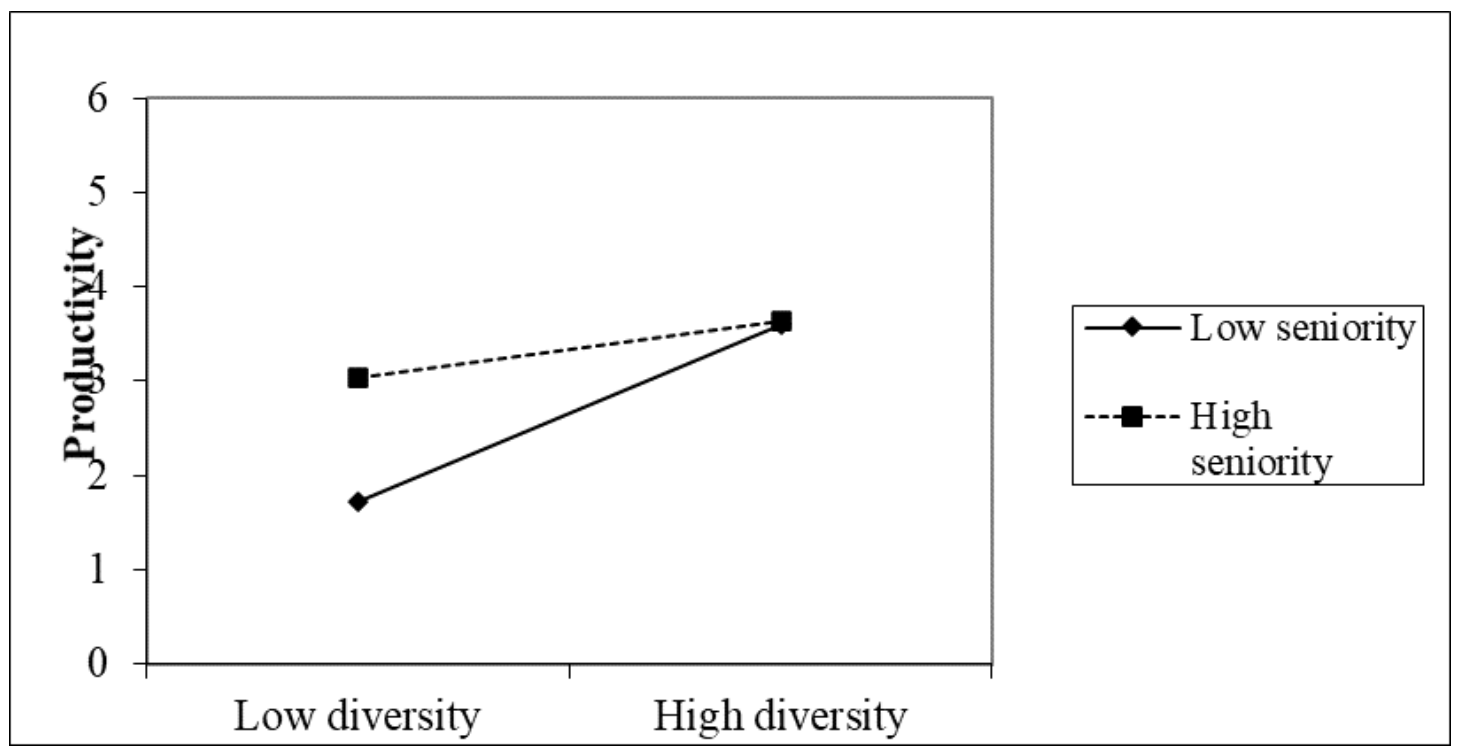

Figure 2: interaction between communication diversity, seniority, and productivity 


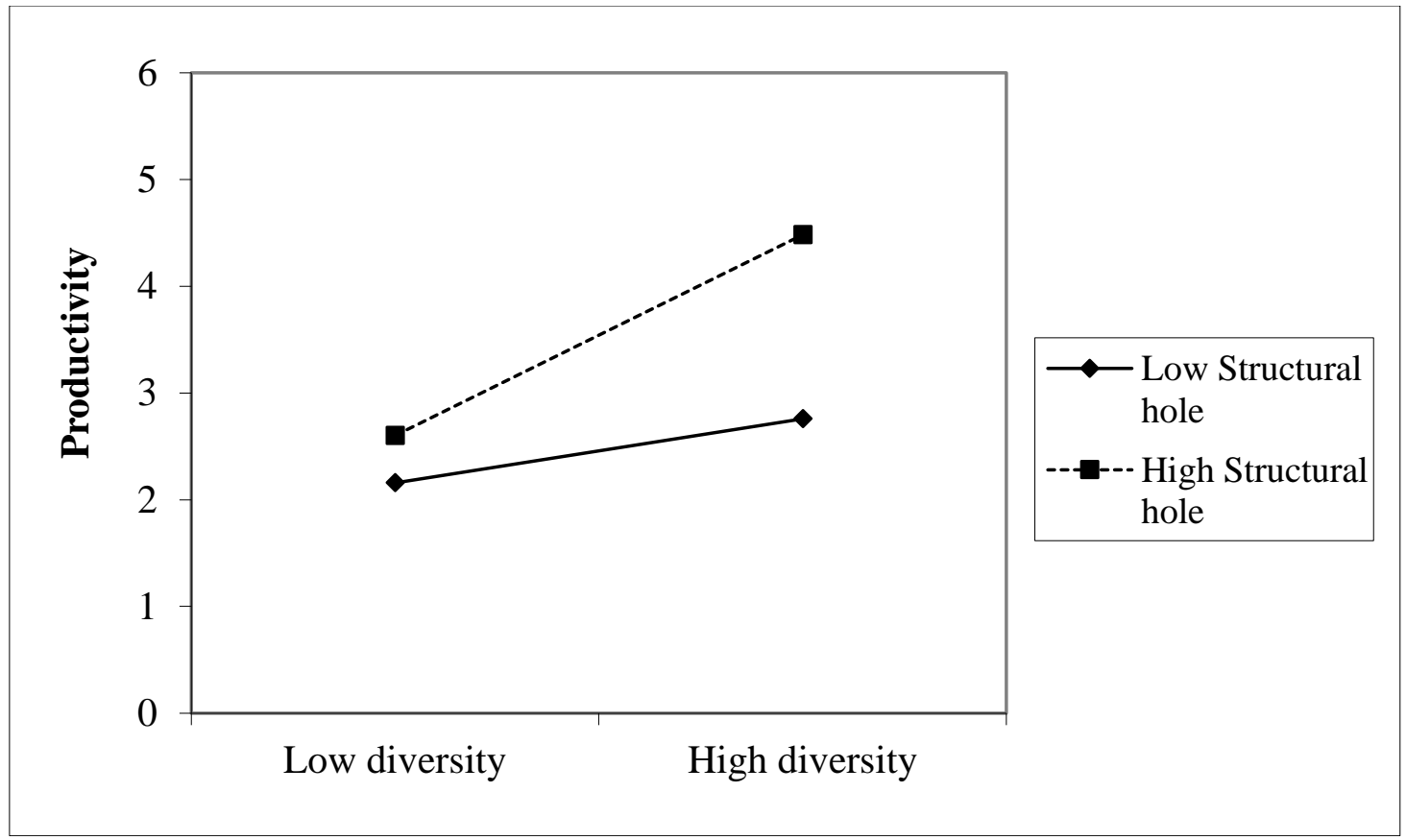

Figure 3: interaction between communication diversity, structural holes, and productivity 
Model 1

B SE

NS

$$
.31
$$

.61

.22

$.62 *$

communication network

Effective size in ego level networks

Diversity X Seniority

Diversity X Effective size

$\mathrm{R}$

$-.32$

.03

$-$

.62

.38

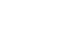

Adjusted $\mathrm{R}^{2}$
$-.32 *$

Mode 2

B $\quad$ SE $\quad \beta$

NS

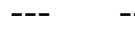

.61

.22

$.62 *$

.54

.16

$.54 *$

$-$

.32

.04

$.32 *$

.64

Table 1: Models predicting number of publications

Note: the provided $B$ scores are of standardized Betas.

NS - Not significant, ${ }^{*} p<.05$. 